including lakes and ponds, streams, springs, wells, and cisterns, and the opinion is expressed that, of all these sources of supply, ground water is the most satisfactory for farm use, because it is least liable to pollution, and that streams and ponds are least trustworthy, because of the ease and frequency with which they are contaminated. Next follows a general description of underground waters and of the means to be adopted for their protection. The information on the subject of wells is detailed and complete, and includes some useful statistics of the cost of the various types, and a tabular statement of their advantages and disadvantages. The "safety distance" from possible sources of pollution is discussed, and that recommended ranges from 100 feet in clay and shale to 200 feet and more in sand and gravel. Boring tools and appliances and the methods of sinking wells are illustrated by diagrams and photographs. Altogether, the manual is one to be cordially commended for careful perusal and study by those dependent for water supply on local and adventitious sources.

It is interesting to note the author's remarks on the use of the "divining rod" for detecting the presence of underground water. $\mathrm{He}$ is of opinion that the alleged automatic deflection of the rod can only be attributable to unconscious muscular action, and that, however honestly the operator may believe in the reality of his powers, the irregularity of the results obtained and the numerous instances of failure recorded indicate that the system is crude, merely experimental, and quite untrustworthy.

B. C.

\section{SCHOOL MEDICAL SERVICE.}

NLY to those familiar with the origins of the medical inspection movement is it credible that, in little more than four years, a system should have developed that needs a Blue-book of upwards of 200 pages even for a brief summary of the work. The second report of Sir George Newman, chief medical officer to the Board of Education, shows that the system of medical inspection is now a fully organised service, producing its multitudes of new facts and propounding innumerable problems of detail.

Section I. deals with administration. The statement of policy is unambiguous. "From the outset the Board took the view that the Medical Inspection of School Children was but one of a number of activities comprised in School Hygiene, and the science and art of School Hygiene itself could not be regarded as an independent science and art which could be pursued in detachment from other studies, but was, in fact, an integral and vital part of that science which, under the name of Public Health, deals with all questions affecting the health and physical condition of the nation" (p. 3). Time alone can fully justify this statement; but, from the beginning, it appealed to the administrative mind. The creation of rival services for inseparable departments of health would have meant that one service would ultimately be superseded. The return of the public health officers into touch with the individual children has undoubtedly restored to that service a unity of purpose that it should never have lost. Preventive medicine includes personal as well as environmental hygiene.

This report contains much material to justify the Board's policy. Of the schedule used, it is important to record that "it is not, and never was, intended to be merely a means of collecting statistics. . . The intention of Parliament was clearly that Medical Inspection should be of a practical character, and have practical rather than academic results" (p. 8). This is a timely warning against the danger of statistics heaped up without any synthetic idea. Nothing more disconcerts the man of practice, who, in this question, is more important as yet than the man of theory. On the whole, this year's reports come well out of the test. The medical men engaged in the medical school service number approximately 986 ; there are 73 women doctors and 289 nurses.

Section II. deals with the physical condition of the children as revealed by medical inspection. There are 1 Annual Report for rgog of the Chief Medical Officer of the Board of
Education Pp. 213. (London: H.M. Stationery Office, rg10.) Price r1d. many interesting percentages as to cleanliness. Pediculosis is all too common, but the systematic schemes of cleansing have effected immense improvements. Incidentally, such schemes will help in the control of less easily perceptible parasites. There is abundant evidence that lavatory accommodation and spray baths are on the increase. But it is certainly disappointing to have to read that here 26 per cent., there 15 per cent., elsewhere 21 per cent., should suffer from vermin. It is, on the other hand, gratifying to find that, in one case, the 26 per cent. of one examination fell to 9 per cent. on the second examination, and this over a total of more than 3000 children. Obviously the activity of the parents has been stimulated by the concentration of attention on the parasitic state. Ring-worm is extremely common. This troublesome and wearisome ailment ought to be extinguished, but its extinction will be difficult. In some counties the cases amount to $I$ in 73 , in athers to $I$ in 45 . In one town the cases were $I$ in 67 , in another $I$ in 1000 . Adenoids and enlarged tonsils and glands have contributed largely to the recorded ailments. So have defective hearing and defective vision. It is impossible to summarise the masses of facts and methods here detailed, but the special attention directed to the respiratory passages may be expected, in the long run, to reduce malnutrition and early tuberculosis. Heart disease should also profit by the inspection. One school medical officer reports " 1.7 per cent. of heart disease among all children examined at five and thirteen years," but he adds that "three times as many suffer from hypertrophy or dilatation" (p. 6r). Another found 2.3 per cent. among five-year-old children and $I \cdot 2$ per cent. among twelve-year-old children. The association of heart disease with rheumatism has been carefully studied by some medical officers. Factors in the production of "dilated heart are anæmia, over-strain, work out of school hours, and cigarette smoking" (p. 62). Of seventysix boys examined for " heart strain due to double digging undertaken in connection with the garden classes," nine showed signs of rheumatic heart disease, and "in eighteen other cases signs of heart strain were discovered" (p. 6r). These facts are of fundamental importance in physical education. The whole question of the "rheumatism of children and adolescents" demands careful investigation.

The section on tuberculosis contains many facts of great importance. "It is interesting to observe that the percentage of tuberculosis among the routine cases is found to be 0.75 in 1909 as against $\mathrm{I} .02$ in 1908 , and among the routine and special cases $I .22$ in $I 909$ as against $\mathrm{I} \cdot 3 \mathrm{I}$ in 1908. Among the special cases, the percentage shows a slight rise-2.02 in 1909 as compared with 1.97 in 1908 " (p. 63). These figures refer to 683,7 I5 children examined in 1909, as compared with 245,000 in 1908 . It is not indicated whether any special reaction methods have been used in diagnosis. The amount of tuberculosis discovered in different localities varies enormously; but the results, if based simply on ordinary clinical inspection, cannot be accepted as indicating the full extent of tubercular prevalence. "The prevalence of phthisis among school children is still a matter upon which great differences exist among school medical officers, and this will continue to be the case until definite standards of diagnosis are introduced" (p. 66). The results recorded abroad from von Pirquet's reaction are in entire discord with the facts recorded here. It is obvious that the whole question of the prevalence of tuberculosis needs investigation de novo. It is a question of primary importance, not merely for practice, but for correct inferences as to heredity. If, as one observer (Dr. Herford, of Altona) finds, that, in an examination of 2594 school children, " 63 per cent. reacted, 50 per cent. of the five-year-old groups, and 94 per cent. of those about to leave school" (p. 66), and if these results be verified, we must suspend judgment on the whole question of prevalence. If those results are correct, masses of statements about " tubercular diathesis" and "intensity of inheritance" fall to the ground. The increase of open-air schools is a gratifying practical result.

Section III., on "following up," contains a good deal of important practice. Section IV. indicates the range of " medical treatment," including the improvement of school arrangements, sanitation, physical exercises, open-air classes, powers under special Acts for blind, deaf, defec- 
tive, epileptic, cooperation with the sanitary authorities as to infectious disease, directions to the parents, school nursing, contributions to hospitals, and establishment of school clinics (p. 94).

Section V. deals with dental disease and dental treatment. Section VI. discusses the problem of special schools for physically defective and epileptic children. Section VII. deals with feeble-minded children; Section VIII. with physical training. There are important appendices on practical questions.

Altogether, the Board of Education and its chief medical officer are to be congratulated on this conspectus of the school medical service, which is rapidly becoming the most important medical service in the country.

\section{OPTICALLY ACTIVE PHOSPHORUS-}

\section{COMPOUNDS.}

$\mathrm{ONE}$ of the most fascinating problems of organic chemistry consists in the attempt to prepare compounds the molecules of which are devoid of planes of symmetry, and are therefore capable (like a screw or a glove) of existing in two forms, usually distinguished as left-handed and right-handed; these have the property of rotating the plane of polarisation of a beam of light to equal extents in opposite directions. Such compounds usually contain an "asymmetric" atom linked to four or five radicles all differing from one another; but compounds have recently been prepared in which the asymmetry cannot be attributed to any single atom, but is a property of the whole molecule (see Nature, vol. lxxxii., p. 266 , December, 1909; this vol., p. 93, March 16). In addition to carbon (linked to four different radicles), asymmetry has been traced by Pope and his colleagues to atoms of pentavalent nitrogen and of tetravalent tin, sulphur, and selenium, whilst Kipping has added tetravalent silicon to the list. The latest addition, that of pentavalent phosphorus, forms the subject of a recent paper by Prof. Meisenheimer in the Berlin Berichte. Two or three years ago this author described a new type of isomerism in the case of nitrogen, the chief characteristic of which was the presence of only four different radicles attached to the pentavalent atom instead of the five that had usually been thought necessary to give rise to optical activity. The conclusions then arrived at have been confirmed by the recent preparation of methylethylaniline oxide,

$$
\begin{aligned}
& \mathrm{CH}_{3} \\
& \mathrm{C}_{2} \mathrm{H}_{5} \\
& \mathrm{C}_{6} \mathrm{H}_{5}
\end{aligned}>\mathrm{N}=\mathrm{O}
$$

in pure crystals, which displayed a large optical activity when dissolved in dry benzene, both the dextro and the lævo forms of the oxide having been separated and examined. The new phosphorus compound is of precisely similar composition, having the formula

$$
\begin{aligned}
& \mathrm{CH}_{3} \\
& \mathrm{C}_{2} \mathrm{H}_{5} \\
& \mathrm{C}_{6} \mathrm{H}_{5}
\end{aligned}
$$

It was prepared by combining diphenylethylphosphine, $\left(\mathrm{C}_{6} \mathrm{H}_{5}\right)_{2} \mathrm{P}\left(\mathrm{C}_{2} \mathrm{H}_{5}\right)$, with methyl iodide, liberating the base by means of silver oxide, and decomposing it by boiling with water, as indicated by the equation

$\left(\mathrm{C}_{6} \mathrm{H}_{5}\right)_{2}\left(\mathrm{C}_{2} \mathrm{H}_{5}\right)\left(\mathrm{CH}_{3}\right) \mathrm{POH}=\mathrm{C}_{6} \mathrm{H}_{6}+\left(\mathrm{C}_{6} \mathrm{H}_{5}\right)\left(\mathrm{C}_{2} \mathrm{H}_{5}\right)\left(\mathrm{CH}_{3}\right)$ PO. The inactive base was resolved by combining it with bromocamphorsulphonic acid-the same agent that was employed twelve years ago by Pope and Peachey in preparing the first active derivatives of asymmetric nitrogenand was separated again from this acid by passing ammonia gas into a solution of the salt in benzene. The ammonium salt was filtered off, and the base separated in needle-shaped crystals of undoubted purity. When redissolved in benzene, the base showed the highly satisfactory rotatory power $[u]_{\mathrm{D}}+33^{\circ} 8^{\circ}[\mathrm{M}]_{\mathrm{D}}+57^{\circ}$.

The experiments now described provide a completed solution of a problem which had already been solved partially by Kipping and Luff (Proc. Chem. Soc., rgog, p. 203). These authors succeeded in isolating two isomeric hydrindamides of the formula

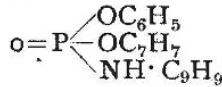

NO. 2 I65, VOL. 86$]$ which differed from one another in optical rotatory power, and almost certainly contained the dextro- and lævorotatory forms of the phosphoric radicle; unfortunately, it was not found possible to separate this radicle from the active hydrindamine which had been used in resolving it, and the final proof of the activity of the phosphoric radicle could not be given.

\section{METEOROLOGICAL REPORTS AND SUMMARIES.}

$M$ ANILA WEATHER BUREAU (1906).-The meteorological observations at the secondary stations have now been published, and form part ii. of the annual report (part i., referring to the central observatory, appeared some time ago). It extends to 404 quarto pages, and includes daily observations and monthly means at the stations which at that time constituted the meteorological service of the Philippines. The observations are carefully collated and examined at the central observatory; some of the stations extend to the Ladrone and Western Caroline Islands, and are of the utmost importance in connection with the origin and premonition of the destructive typhoons that frequently advance from that part of the Pacific Ocean. They are also used in the preparation of the valuable monthly weather bulletins of the bureau, to which we have often had occasion to refer.

Toronto Observatory (1908).-During the year covered by this report, the building used since 1855 was replaced by a new Canadian Meteorological Office and Observatory. The following values are taken from the useful summary of results given for each month and the year, with differences from the average of the past sixty-nine years. The extremes of temperature are taken from the maximum and minimum thermometers in the Stevenson screen. Highest temperature (July 30), $9 \mathrm{I} \cdot 5^{\circ}$ lowest (February 4), $-17.4^{\circ}$; highest on record, $99.2^{\circ}$; lowest, $-26.5^{\circ}$. Mean of highest readings in 1908 , $55.8^{\circ}$; of lowest, $37.7^{\circ}$. Mean from max. and min., $46.7^{\circ}$, being $2 \cdot 7^{\circ}$ above the average. Highest solar radiation (August 4), $128.3^{\circ}$; lowest night radiation (February 4) $-2 \mathrm{I} \cdot 0^{\circ}$. Rainfall, $2 \mathrm{I} \cdot 7^{2}$ inches; depth of snowfall, 77.8 inches. Percentage of possible sunshine, 47 , the average for the past twenty-seven years being 42 per cent. The mean W. declination was $5^{\circ} 54 \cdot \mathrm{I}^{\prime}$; dip, $74^{\circ} 36 \cdot 9^{\prime}$.

Korea Meteorological Observations (r908-9).-These valuable observations and results are in continuation of those referred to in our issue of May ig last. The following statistics refer to Chemulpo Observatory (lat. $37^{\circ} 29^{\prime}$ N., long. $126^{\circ} 32^{\prime}$ E.) for rgog. Temperature :mean maximum, $58.5^{\circ}$; absolute, $93^{\circ} 2^{\circ}$ (in August); mean minimum, $44 \cdot \mathrm{I}^{\circ}$; absolute, $8 \cdot \mathrm{I}^{\circ}$ (in December); annual mean, $50 \cdot 7^{\circ}$ (normal, $5 \mathbf{1} \cdot 1^{\circ}$ ); rainfall, 25 inches (normal, 37.7 inches), days, 96 ; sunshine, 2746 hours (62 per cent. of possible amount). The instruments and methods are the same as those at Japanese stations.

Odessa Observatory (I909).-We are glad to see that Prof. Stankevitsch proposes to cooperate regularly in the international researches of the upper air. Two kite ascents were made in December, but only moderate altitudes were reached. At present this important work can cnly be carried out under difficulties, as the director and his principal observers are engaged at the University. The annua! summary shows that the mean temperature was $5^{\circ} \cdot 7^{\circ}$; January, $21 \cdot 2^{\circ}$; July, $74 \cdot 3^{\circ}$; absolute maximum, $94.8^{\circ}$ (in July), minimum, $-7.2^{\circ}$ (in January). Rainfall, $14 \frac{1}{2}$ inches, on 98 days; fog, 58 days; frost, 95 days. Appendices give the normal values for a number of years (see Natuke, February 16), also rainfall and thunderstorms, at stations in south-west Russia.

India Weather Review, Annual Summary (r9o9).-The greater part of this work is taken up by the calculation of the monthly and annual departures of each element from the normal values, and a useful discussion of the results under four seasons: cold-weather period (January and February), hot-weather period (March-May), southwest monsoon period (June-September), period of the retreating south-west monsoon (October-December). These are followed by abstracts of the observations made in India and a few extra stations, and by maps relating to rainfall, and the tracks of cyclonic storms formed in the 